\title{
Novel Coronavirus Disease 2019 (COVID-19), the Attack Risk in 21 Century: An Overview
}

\author{
Raghda Alsayed ${ }^{1}$, Sara J. kadhim², Wedad H. Al-Dahhan', Mohammed H. Al-Mashhadani', \\ Rasha Raheem ${ }^{3}$ and Emad Yousif ${ }^{1^{*}}$
}

${ }^{1}$ Department of Chemistry, College of Science, Al-Nahrain University, Iraq

${ }^{2}$ Ministry of Education, Iraq

${ }^{3}$ Department of Pathology, Microbiology, and Immunology, University of South Carolina School of Medicine, USA

\begin{abstract}
Consistently human has assaulted by animals that don't see by eyes pulverizing immense quantities of mankind and making organization and scientists prepared and attempting to stand up to it and find something to shield from it. The development of SARS-CoV-2, since the extreme intense respiratory disorder coronavirus (SARS-CoV) in 2002 and Middle East respiratory disorder coronavirus (MERS-CoV) in 2012, denoted the third presentation of an exceptionally pathogenic and enormous scope plague coronavirus into the human populace in the twenty-first century. The clinical manifestations of COVID-19 patients incorporate fever, hack, exhaustion and a little populace of patients seemed gastrointestinal contamination side effects. The older and individuals with basic illnesses are vulnerable to contamination and inclined to genuine results. On 30 January 2020, World Health Organization (WHO) authoritatively proclaimed the COVID-19 pandemic as a general health emergency of global concern.
\end{abstract}

Keywords

Covid-19, Coronavirus, Pandemic, SARS-CoV, Novel coronavirus pneumonia

\section{Introduction}

In late December 2019, a flare-up of an obscure disease called pneumonia of unknown reason happened in Wuhan, Hubei region, China [1]. The causative infection has been incidentally named as serious intense respiratory disorder coronavirus 2 (SARS-CoV-2) and the pertinent tainted sickness has been named as coronavirus malady 2019 (COVID-19) by the World Health Organization [2]. Corona viruses (CoVs) are a gathering of profoundly differing, encompassed, positive-sense, also single-stranded RNA viruses 5 . They cause a few ailments including respiratory, enteric, hepatic, also neurological frameworks with fluctuate seriousness among people as well as creatures. In the course of recent decades, two novel CoVs, extreme intense respiratory disorder CoV (SARS-CoV) also Middle East respiratory disorder CoV (MERSCoV), have developed and cause serious human infections [3] (Table 1).

\section{SARS-CoV}

Severe acute respiratory syndrome coronavirus (SARSCoV) - infection recognized in 2002. The SARS contamination immediately spread from China to other Asian nations. It is a wrapped, positive-sense, single-stranded RNA infection which contaminates the epithelial cells inside the lungs [4]. During the time of disease, there were 8,098 detailed cases of SARS also 774 deaths. This implies the infection executed around 1 out of 10 individuals who were tainted. The death rate was a lot higher for those more than 60-years of age, with death rates moving toward half for this subset (50\%) of patients [5]. Treatment for it was anti-infection agents to treat microorganisms that cause pneumonia also high portions of steroids to diminish expanding in the lungs.

\section{MERS-CoV}

Middle East respiratory syndrome coronavirus (MERSCoV), otherwise called camel influenza, is a beta coronavirus [6]. The primary recognized case happened in Saudi Arabia also most cases have happened in the Arabian Peninsula. (MERS-CoV) is a species with single-stranded RNA having a

*Corresponding author: Emad Yousif, Department of Chemistry, College of Science, Al-Nahrain University, Baghdad, Iraq

Accepted: March 01, 2021

Published online: March 03, 2021

Citation: Alsayed R, Kadhim SJ, Al-Dahhan WH, et al. (2021) Novel Coronavirus Disease 2019 (COVID-19), the Attack Risk in 21 Century: An Overview. Clin J HIV AIDS 5(1):51-54 
Citation: Alsayed R, Kadhim SJ, Al-Dahhan WH, et al. (2021) Novel Coronavirus Disease 2019 (COVID-19), the Attack Risk in 21 Century: An Overview. Clin J HIV AIDS 5(1):51-54

Table 1: CoV that causes disease in human.

\begin{tabular}{|l|l|l|l|}
\hline Coronavirus & Intermediate host & Affected host & Cell receptor \\
\hline SARS-CoV & Raccoon & Humans & ACE2 \\
\hline MERS-CoV & Dromedary camels & Humans & DPP4 \\
\hline SARS-CoV2 & Bat & Humans & ACE2 \\
\hline
\end{tabular}

Table 2: The highest 5 countries COVID-19 laboratory-confirmed cases and deaths in the Western Pacific Region. Data as of 10 July 2020.

\begin{tabular}{|l|l|l|}
\hline Reporting Country & Total confirmed cases & Total deaths \\
\hline China & 85,445 & 4,648 \\
\hline Japan & 20,719 & 982 \\
\hline Republic of Korea & 13,338 & 288 \\
\hline Australia & 9,059 & 106 \\
\hline Malaysia & 8,683 & 121 \\
\hline
\end{tabular}

Table 3: The highest 5 countries COVID-19 laboratory-confirmed cases and deaths in the European Region. Data as of 10 July 2020.

\begin{tabular}{|l|l|l|}
\hline Reporting Country & Total confirmed cases & Total deaths \\
\hline The United Kingdom & $2,87,625$ & 44,602 \\
\hline Spain & $2,53,056$ & 28,401 \\
\hline Italy & $2,42,363$ & 34,926 \\
\hline Germany & $1,98,178$ & 9,054 \\
\hline France & $1,60,783$ & 29,886 \\
\hline
\end{tabular}

place with the variety beta coronavirus which is particular from SARS coronavirus also the basic cold coronavirus. The infection develops promptly on Vero cells as well as LLC-MK2 cells [7]. The WHO prescribed testing calculation is to begin with an upE RT-PCR and if positive affirm with ORF 1A examine or RdRp or $\mathrm{N}$ quality arrangement test for affirmation. On the off chance that both an upE and optional examine are sure it is viewed as an affirmed case [8]. Analysts are researching various approaches to battle the episode of Middle East respiratory disorder coronavirus, including utilizing interferon, chloroquine, chlorpromazine, loperamide, lopinavir [9]. According to WHO (MERS) affirmed cases also passing's from June 2012 to January 2020 is 2519 stops and 866 deaths.

\section{COVID-19}

Coronavirus disease 2019 (COVID-19) additionally know as: 2019-nCoV intense respiratory malady, Novel coronavirus pneumonia, Wuhan pneumonia [10] also Disease $X$ as indicated by the WHO [11]. The ailment was first recognized in December 2019 in Wuhan as well as fastly spreading the world over. The WHO considered as a pandemic situation. In 10 July 2020 the complete universally affirmed is $12,102,328$ and 551,046 passings. In all out Coronavirus patients passed on, curiously the most noteworthy number has a place with Americas for example 276,370 passings. The loss of life is trailed by Europe $(202,341)$ also Eastern Mediterranean $(29,690)$ (Table 2, Table 3 and Table 4).

Both MERS-CoV also SARS-CoV have a lot higher case ca-
Table 4: The highest 5 countries COVID-19 laboratory-confirmed cases and deaths in the Eastern Mediterranean Region. Data as of 10 July 2020.

\begin{tabular}{|l|l|l|}
\hline Reporting Country & Total confirmed cases & Total deaths \\
\hline Iran (Islamic Republic of) & $2,50,458$ & 12,305 \\
\hline Pakistan & $2,43,596$ & 5,058 \\
\hline Saudi Arabia & $2,23,327$ & 2,100 \\
\hline Qatar & $1,02,110$ & 142 \\
\hline United Arab Emirates & 53,577 & 328 \\
\hline
\end{tabular}

sualty rates ( $40 \%$ and $10 \%$, separately). Despite the fact that the present SARS-CoV-2 offers $79 \%$ of its genome with SARS$\mathrm{CoV}$, it seems, by all accounts, to be significantly more transmissible [12].

\section{Virus characteristic}

Coronavirus disease 2019 (COVID-19) is an irresistible ailment brought about by extreme intense respiratory disorder coronavirus 2 (SARS-CoV-2) [13]. Full-genome sequencing also phylogenic investigation showed that coronavirus that cause COVID-19 is a beta coronavirus in a similar subgenus as the serious intense respiratory disorder (SARS) infection, however in an alternate clade. Structure of receptor-restricting quality locale is fundamentally the same as that of the SARS coronavirus, also the infection has been appeared to utilize a similar receptor, angiotensin-converting enzyme2 (ACE2), for cell entry [14]. In a phylogenetic investigation of 103 strains of SARS-CoV-2 from China, two unique sorts of SARS-CoV-2 were distinguished, assigned sort $L$ (representing 70 percent of the strains) also type $S$ (representing 30 percent) [15]. Both SARS-CoVs enter cell by means of angiotensin-converting enzyme 2 (ACE2) receptor, which is generally copious in sort II alveolar cells of lungs. The infection utilizes an uncommon surface glycoprotein called a "spike" (peplomer) to associate with ACE2 also enter host cell [16].

\section{Transmission}

Comprehension of transmission chance is inadequate. Is thought to happen chiefly from individual to individual through respiratory beads, taking after the spread of flu. With bead transmission, infection discharged in respiratory emissions when an individual with contamination hacks, sniffles, or talks can taint someone else in the event that it reaches the mucous layers; disease can likewise happen in the event that an individual contacts a tainted surface and, at that point contacts their eyes, nose, or mouth. Beads ordinarily don't travel multiple meters and don't wait noticeable all around. The announced paces of transmission from a person with symptomatic disease fluctuate by area and contamination 
Citation: Alsayed R, Kadhim SJ, Al-Dahhan WH, et al. (2021) Novel Coronavirus Disease 2019 (COVID-19), the Attack Risk in 21 Century: An Overview. Clin J HIV AIDS 5(1):51-54

Table 5: Clinical symptoms associated with COVID-19.

\begin{tabular}{|l|l|l|}
\hline Clinical types & Symptoms & $\%$ \\
\hline Mild & Non pneumonia or mild pneumonia & $81 \%$ \\
\hline Severe & Dyspnea, blood oxygen saturation, lung infiltrates within 24/48 hours & $14 \%$ \\
\hline Critical & Multi organ dysfunction, Respiratory failure & $5 \%$ \\
\hline
\end{tabular}

control intercessions. As per a joint WHO-China report, the pace of auxiliary COVID-19 ran from 1 to 5 percent among a huge number of close contacts of affirmed patients in China [17].

\section{Diagnosis}

The WHO has distributed a few testing conventions for disease [18]. The standard strategy for testing is continuous converse interpretation polymerase chain response [18]. The test is ordinarily done on respiratory examples got by a nasopharyngeal swab, Results are commonly accessible inside a couple of hours to two days [19]. The FDA endorsed the (primary purpose of-care test) on 21 March 2020 for use [20].

\section{Prevention}

To diminish the odds of contamination:

- Staying at home.

- Washing hands with cleanser water regularly just as for in any event 20 seconds.

- Avoiding crowded places also mask should be close to face, covering nose also mouth completely. At the point when the cover is on or being evacuated, hands must not contact the out layer of the veil to stay away from hands defilement.

- Alcohol-based sanitization wipes ought to be utilized for hand cleaning and cleansing.

- Reusable goggles ought to be quickly sanitized and dried each time after use.

- Also suggest legitimate hand cleanliness after any hack or sniffle.

\section{Symptomatic infection}

A few cases in China at first gave just chest snugness also palpitations [21]. In March 2020 there were reports showing that loss of the feeling of smell (anosmia) might be a typical indication among the individuals who have gentle disease [22]. As is normal with contaminations, there is a postponement between the minute when an individual is tainted with the infection and when they create indications. This is known as the brooding time frame. The hatching time frame for COVID-19 is regularly five to six days yet may go from two to 14 days [23].

The most common symptoms:

- Fever

- Headache

- Dry cough
- Shortness of breath

- Sore throat

In a report from the Chinese Center for Disease Control also Prevention that included roughly 44,500 affirmed contaminations with an estimation of sickness seriousness, patients can be named gentle, extreme, also basic types [24], as indicated by the Table 5 .

\section{Risk factors}

Among patients with cutting edge age and clinical comorbidities, COVID-19 is much of the time extreme. Males have contained a lopsidedly high number of passings in accomplices from China also Italy [25]. The United States Centers for Disease Control als Prevention (CDC) additionally incorporates immune compromising conditions, extreme heftiness (BMI $\geq 40$ ), also liver ailment as potential hazard factors for serious illness [26]. Patients with serious infection have additionally been accounted for to have higher hazard factors like: Cardiovascular malady, chronic kidney disease, Cancer, Chronic lung ailment, Diabetes mellitus and Hypertension [27].

\section{Recommendation}

Since the main reports of COVID-19, contamination has spread to incorporate in excess of a million affirmed cases around the world, provoking the WHO to pronounce a general wellbeing crisis in late January 2020 and describe it as a pandemic in March 2020. The chance of COVID-19 ought to be considered fundamentally in patients with fever also additionally respiratory tract indications. Restrictions in testing limit may block testing all patients with suspected contamination; proposed needs incorporate hospitalized patients, symptomatic social insurance laborers, also symptomatic people who have hazard factors for serious sickness. To decrease the danger of transmission in the network, people ought to be encouraged to wash hands tirelessly, practice respiratory cleanliness (eg, spread their hack), and keep away from groups also close contact with sick people, if conceivable. Social separating is prescribed in areas that have a network transmission.

\section{References}

1. Wuhan Municipal Health Commission (2019) Report of clustering pneumonia of unknown etiology in Wuhan City.

2. Zumla A, Chan JF, Azhar El, et al. (2016) Coronaviruses-drug discovery and therapeutic options. Nat Rev Drug Discov 15: 327347.

3. Chan JF, Lau SK, To KK, et al. (2015) Middle East respiratory syndrome coronavirus: Another zoonotic betacoronavirus causing SARS-like disease. Clin Microbiol Rev 28: 465-522. 
4. Fehr AR, Perlman S (2015) Coronaviruses: An Overview of their replication and pathogenesis. Methods Mol Biol 1282: 1-23.

5. Sørensen MD, Sørensen B, Gonzalez-Dosal R, et al. (2006) Severe acute respiratory syndrome (SARS): Development of diagnostics and antivirals. Ann N Y Acad Sci 1067: 500-505.

6. Assiri A, Al-Tawfiq JA, Al-Rabeeah AA, et al. (2013) Epidemiological, demographic, and clinical characteristics of 47 cases of Middle East respiratory syndrome coronavirus disease from Saudi Arabia: A descriptive study. Lancet Infect Dis 13: 752761.

7. Briese T, Mishra N, Jain K, et al. (2014) Middle East respiratory syndrome coronavirus quasispecies that include homologues of human isolates revealed through whole-genome analysis and virus cultured from dromedary camels in Saudi Arabia. mBio 5: e01146.

8. (2014) Laboratory Testing for Middle East Respiratory Syndrome Coronavirus.

9. Cheng KW, Cheng SC, Chen WY, et al. (2015) Thiopurine analogs and mycophenolic acid synergistically inhibit the papain-like protease of Middle East respiratory syndrome coronavirus. Antiviral Research 115: 9-16.

10. Campbell C (2020) The Wuhan Pneumonia Crisis Highlights the Danger in China's Opaque Way of Doing Things.

11. Mohammed H, Al-mashhadani, Alsayed R, et al. (2020) An overview of possible therapeutic approaches against Novel Coronavirus disease 2019 Pandemic. Al-Nahrain Journal of Science 6-11.

12. Emmie de Wit, Neeltje van Doremalen, Darryl Falzarano, et al. (2016) SARS and MERS: Recent insights into emerging coronaviruses. Nat Rev Microbiol 14: 523-534.

13. World Health Organization (WHO) (2020) Naming the coronavirus disease (COVID-19) and the virus that causes it.

14. Zhou P, Yang XL, Wang XG, et al. (2020) A pneumonia outbreak associated with a new coronavirus of probable bat origin. Nature 588: E6.
15. Tang X, Wu C, Li X, et al. (2020) On the origin and continuing evolution of SARS-CoV-2. Natl Sci Rev 3: 36.

16. Letko M, Marzi A, Munster V (2020) Functional assessment of cell entry and receptor usage for SARS-CoV-2 and other lineage B beta coronaviruses. Nat Microbiol 5: 562-569.

17. (2020) Report of the WHO-China Joint Mission on Coronavirus Disease 2019 (COVID-2019). 16-24.

18. Centers for Disease Control and Prevention (2020) 2019 Novel Coronavirus (2019-nCoV) Situation Summary.

19. Centers for Disease Control and Prevention (2020) Real-Time RTPCR Panel for Detection 2019-nCoV.

20. (2020) Coronavirus (COVID-19) Update: FDA Issues first Emergency Use Authorization for Point of Care Diagnostic (Press release). FDA.

21. U.S. Centers for Disease Control and Prevention (CDC) (2020) Symptoms of Coronavirus.

22. Alsayed R, Kadhom M, Yousif E, et al. (2020) An Epidemiological Characteristic of the COVID-19 Among Children. Platinum Open Access Journal 9: 1156-1164.

23. World Health Organization (2020) Coronavirus disease 2019 (COVID-19): Situation report. 29.

24. Wu Z, McGoogan JM (2020) Characteristics of and important lessons from the Coronavirus Disease 2019 (COVID-19) Outbreak in China: Summary of a Report of 72314 cases from the Chinese center for disease control and prevention. JAMA 7: 1239-1242.

25. Chen T, Wu D, Chen H, et al. (2020) Clinical characteristics of 113 deceased patients with coronavirus disease 2019: Retrospective study. BMJ 368: 1091.

26. https://www.cdc.gov/coronavirus/2019-ncov/need-extraprecautions/people-at-higher-risk.html

27. Liang W, Guan W, Chen R, et al. (2020) Cancer patients in SARSCoV-2 infection: A nationwide analysis in China. Lancet Oncol 21: 335-337.

DOI: $10.36959 / 695 / 570$

Copyright: (C) 2021 Alsayed R, et al. This is an open-access article distributed under the terms of the Creative Commons Attribution License, which permits unrestricted use, distribution, and reproduction in any medium, provided the original author and source are credited. 